\title{
OPEN Predicting in-season maize (Zea mays L.) yield potential using crop sensors and climatological data
}

\author{
Jagmandeep Dhillon ${ }^{1 凶}$, Lawrence Aula² ${ }^{2}$ Elizabeth Eickhoff ${ }^{2} \&$ William Raun $^{2}$
}

The environment randomly influences nitrogen $(\mathrm{N})$ response, demand, and optimum $\mathrm{N}$ rates. Field experiments were conducted at Lake Carl Blackwell (LCB) and Efaw Agronomy Research Station (Efaw) from 2015 to 2018 in Oklahoma, USA. Fourteen site years of data were used from two different trials, namely Regional Corn (Regional) and Optimum $\mathrm{N}$ rate (Optimum $\mathrm{N}$ ). Three algorithms developed by Oklahoma State University (OSU) to predict yield potential were tested on both trials. Furthermore, three new models for predicting potential yield using optical crop sensors and climatological data were developed for maize in rain-fed conditions. The models were trained/built using Regional and were then validated/tested on the Optimum $\mathrm{N}$ trial. Out of three models, one model was developed using all of the Regional trial (combined model), and the other two were prepared from each location LCB and Efaw model. Of the three current algorithms; one worked best at predicting final grain yield at LCB location only. The coefficient of determination $R^{2}=0.15$ and 0.16 between actual grain yield and predicted grain yield was observed for Regional and Optimum $\mathrm{N}$ rate trials, respectively. The results further indicated that the new models were better at predicting final grain yield except for Efaw model $\left(R^{2}=0.04\right)$ when tested on optimum $N$ trial. Grain yield prediction for the combined model had an $R^{2}=0.31$. The best yield prediction was obtained at $L C B$ with an $R^{2}=0.52$. Including climatological data significantly improved the ability to predict final grain yield along with using mid-season sensor data.

The three most yield-limiting nutrients in cereal crop production are $\mathrm{N}$, phosphorus $(\mathrm{P})$, and potassium $(\mathrm{K})$. Globally, $\mathrm{N}$ consumption has increased eight times ${ }^{1}, \mathrm{P}$ increased $3.5^{2}$ and $\mathrm{K}$ consumption has increased three times $^{3}$, since the year 1961. Undoubtedly, $\mathrm{N}$ remains the most consumed nutrient worldwide.

A review in 1999 encompassing global $\mathrm{N}$ use and cereal crop production found that nitrogen use efficiency (NUE) in cereal crops was $33 \%{ }^{4}$. A lot of research has been devoted to improving NUE in crops grown worldwide ${ }^{4-6}$. Lassaletta et al. ${ }^{5}$ noted that considering the present situation increasing $\mathrm{N}$ fertilization would not result in a yield increase. Alternatively, they suggested improvement of agronomic practices to be an efficient strategy. Raun and Johnson ${ }^{4}$ proposed various approaches through which NUE could be improved, including site-specific $\mathrm{N}$ management.

Historically, yield goals have been used for estimating preplant ${ }^{7}$ and in-season $\mathrm{N}$ rates $^{8}$. However, their adequacy has been refuted in winter wheat ${ }^{9}$, and maize ${ }^{10}$. Rodriguez et al. ${ }^{10}$ deduced data-intensive fertilizer management as a more efficient $\mathrm{N}$ management strategy. Crop optical sensing has been effectively used to identify $\mathrm{N}$ deficiency in the field and determine in-season $\mathrm{N}$ fertilizer recommendation ${ }^{11-17}$.

The first and critical step for sensor-based site-specific nutrient management is in-season prediction of yield potential ${ }^{3,8,17}$, for which an algorithm is required ${ }^{18,19}$. The optical sensors use normalized difference vegetation indices (NDVI) from crop canopy reflectance of red and near-infrared wavebands to estimate chlorophyll content, crop N content, biomass, and yield predictions ${ }^{16,20-22}$. To improve yield estimates, Raun et al. ${ }^{7}$ introduced an in-season estimate of yield (INSEY), using NDVI divided by growing degree days where yield was possible $(G D D>0)$ in winter wheat. Maize algorithms for determining $\mathrm{N}$ recommendations utilizes the measurement of the crop grain yield potential at the time of sensing along with a response index (RI), a ratio of N-rich NDVI compared to a deficient $\mathrm{N}$ area ${ }^{23}$.

Numerous researchers have tried to improve the in-season estimate of yield by including other variables in conjunction with NDVI and GDD. Girma et al. ${ }^{24}$ combined chlorophyll content, plant height, and total N uptake along with NDVI as good predictors of final wheat grain yield. Walsh et al.$^{25}$ included soil moisture at $0.05 \mathrm{~m}$ depth with NDVI to accurately predict wheat grain yield. Bushong et al. ${ }^{8}$ assimilated NDVI, days of potential

${ }^{1}$ Department of Plant and Soil Sciences, Mississippi State University, 470 Dorman Hall, Starkville, MS 39762, United States. ${ }^{2}$ Department of Plant and Soil Sciences, Oklahoma State University, 368 Agricultural Hall, Stillwater, OK 74078, United States. ${ }^{\varpi}$ email: Jagman.dhillon@msstate.edu 


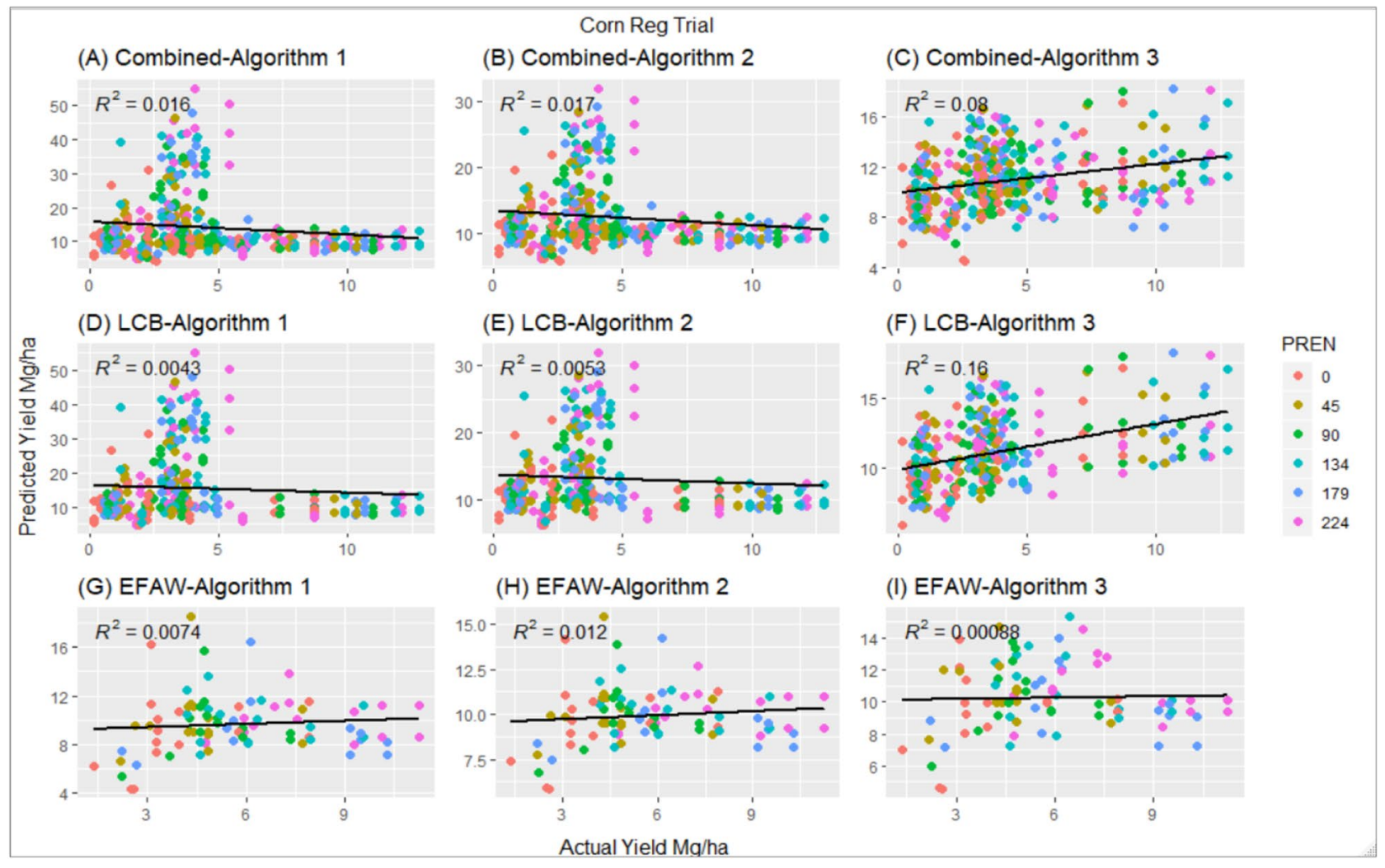

Figure 1. Correlation between actual yield and predicted yield using three current algorithms at different preplant $\mathrm{N}$ rates (PREN), Corn Regional trial, using combined data with algorithm 1 (A), using combined data with algorithm 2 (B), using combined data with algorithm 3 (C), using LCB data with algorithm 1 (D), using LCB data with algorithm 2 (E), using LCB data with algorithm 3 (F), using Efaw data with algorithm 1 (G), using Efaw data with algorithm 2 (H), using Efaw data with algorithm 3 (I).

growth (based on temperature and soil moisture), and a stress index (amount of plant-available water divided by the amount of water required to maintain yield) to accurately predict in season wheat yield estimates. In maize, a combined model using plant height along with NDVI was used to successfully predict by-plant corn grain yields at the V8 growth stage ${ }^{21,26}$. Sharma et $\mathrm{al}^{15}$ included soil moisture in a polynomial model of yield prediction and concluded it to be better than exponential models. Machine learning (ML) offers another new possibility to predict $\mathrm{N}$ fertilizer recommendation in maize. The difference between ML and traditional statistics is the inclusion of more variables in machine learning ${ }^{27}$. Puntel et al. ${ }^{28}$ used soil depth, precipitation, heat stress, nitrate-N at planting, and residue amount, out of 54 variables used in the study, to predict economic optimum $\mathrm{N}$ rate.

Morris et al. ${ }^{13}$ found it difficult to accurately predict the amount of $\mathrm{N}$ needed by maize and inferred that current techniques are inadequate in $\mathrm{N}$ recommendations. In their review, they concluded that uncontrollable environmental factors and their interaction with other considerations such as $\mathrm{N}$ source, timing and placement, plant genetics, and soil characteristics need to be combined to make better $\mathrm{N}$ rate recommendations. Recently, Raun et al. ${ }^{29}$ suggested independent estimation of multiple random variables for mid-season algorithms due to erratic effect environment has on $\mathrm{N}$ demand and final grain yield.

The studied area in this work is in the Southern Great Plains (SGP). The SGP mainly comprises of Texas, Kansas, and Oklahoma, and this region frequently encounters periods of prolonged drought, erratic rainfall, and variable air temperatures ${ }^{30}$. The variability that is encountered in precipitation and temperature within SGP affects nutrient management for various crops. Consequently, the first objective of this study was to assess the efficiency of three current algorithms developed by Oklahoma State University (OSU) to predict yield potential. Furthermore, the second objective was to create three new models for predicting potential yield using optical crop sensors and climatological data for maize under rainfed conditions.

\section{Results}

Evaluation of current algorithms. All the three algorithms performed poorly when tested on combined data for both locations for the Regional trial (Fig. 1). There was a weak correlation among predicted and actual grain yield evident by the lower coefficient of determination $\left(\mathrm{R}^{2}<0.08\right)$.

At LCB algorithms 1 and 2 were unable to predict yields. The predicted yield with algorithm 1 and 2 , at higher PREN, resulted in the prediction of yields up to $50 \mathrm{Mg} \mathrm{ha}^{-1}$. However, algorithm 3 performed slightly better with an $\mathrm{R}^{2}=0.16$. Similar to combined sites, all the algorithms were unable to predict actual grain yield at Efaw. Similar to the Regional trial, all three algorithms performed poorly at predicting final grain yield in Optimum 


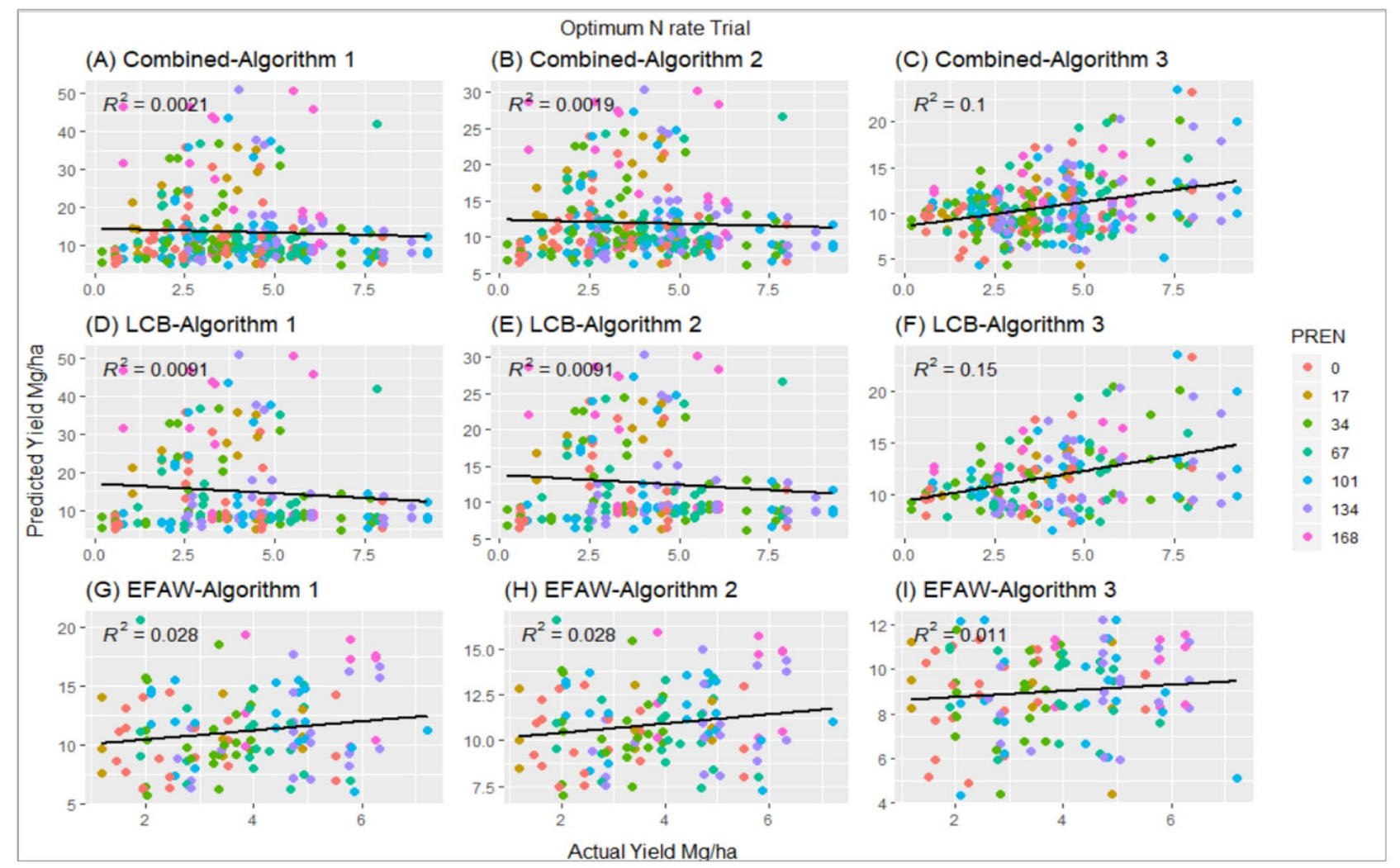

Figure 2. Correlation between actual yield and predicted yield using three current algorithms at different preplant $\mathrm{N}$ rates (PREN), Optimum $\mathrm{N}$ rate trial, using combined data with algorithm 1 (A), using combined data with algorithm 2 (B), using combined data with algorithm 3 (C), using LCB data with algorithm 1 (D), using LCB data with algorithm 2 (E), using LCB data with algorithm 3 (F), using Efaw data with algorithm 1 (G), using Efaw data with algorithm 2 (H), using Efaw data with algorithm 3 (I).

\begin{tabular}{|c|c|c|}
\hline Data & Model & Adjusted $\mathrm{R}^{2}$ \\
\hline Combined & $\begin{array}{l}-2.751386 \mathrm{e}+02+9.087027 \mathrm{e}-03 \times \mathrm{PREN}+3.165433 \mathrm{e}+00 \times \mathrm{NDVI}-3.346925 \mathrm{e}-03 \times \mathrm{GDD}+8.5996 \\
44 \mathrm{e}+00 \times \text { S25AVG.7 }+3.228292 \mathrm{e}+01 \times \text { FWI } 25.4+7.775841 \mathrm{e}+00 \times \text { FWI } 25.6+1.190534 \mathrm{e}+01 \times \mathrm{FW} \\
\mathrm{I} 25.7+6.451529 \mathrm{e}+00 \times \text { FWI } 25.9\end{array}$ & 0.83 \\
\hline Lake Carl Blackwell & $\begin{array}{l}-6.408236013+0.006625366 \times \text { PREN }+3.271162048 \times \text { NDVI }-0.003379189 \times \text { GDD }-0.019196793 \\
\times \text { AprR }+0.331984242 \times \text { SAVG } 8+9.377433891 \times \text { FWI } 25.9\end{array}$ & 0.85 \\
\hline Efaw & $-94.63931672+0.01725896 \times$ PREN $-1.14674051 \times$ BAVG. $8+4.74565389 \times$ S25AVG.7 & 0.67 \\
\hline
\end{tabular}

Table 1. New regression models for predicting final grain yields. The acronyms are explained in Table 4 .

$\mathrm{N}$ trial (Fig. 2). Lower $\mathrm{R}^{2}$ were observed with all three algorithms for all the combined data. At LCB, algorithm 3 was able to explain $16 \%$ of the actual yield, where algorithm 1 and 2 explained only $0.5 \%$. None of the algorithms were able to explain more than $1.2 \%$ of actual grain yield at Efaw location.

New models. All three models built using Regional data are reported in Table 1 . The first model was developed using all seven site years of Regional data and included 8 out of 66 explanatory variables included in this study. The Cp, AIC, BIC, and adjusted $\mathrm{R}^{2}$, all selected eight variables as an optimal model. Based on their importance, the first variable included in the model was PREN, followed by NDVI, and GDD. The next variable added was the average monthly soil temperature at $250 \mathrm{~mm}$ under sod for July (S25AVG-7). The last four variables included were fractional water indices at $250 \mathrm{~mm}$ for April (FWI25-4), June (FWI25-6), July (FWI25-7), and September (FWI25-9). This model could explain 83\% of the final grain yield (Table 1).

The second model trained using LCB Regional data included six variables as per Cp, AIC, BIC, and adjusted $\mathrm{R}^{2}$ (Table 1). This model included PREN, NDVI, GDD, and FWI25-9, similar to the combined model. Furthermore, it included average precipitation for April (AprR) and average monthly soil temperature $100 \mathrm{~mm}$ under sod (SAVG-8). This was the best model of the three new models with the ability to explain $85 \%$ of final grain yield.

The third model only included three variables and could only clarify $67 \%$ of the final yield and was built using Efaw Regional data (Table 1). The first variable included in this model was also PREN, followed by 


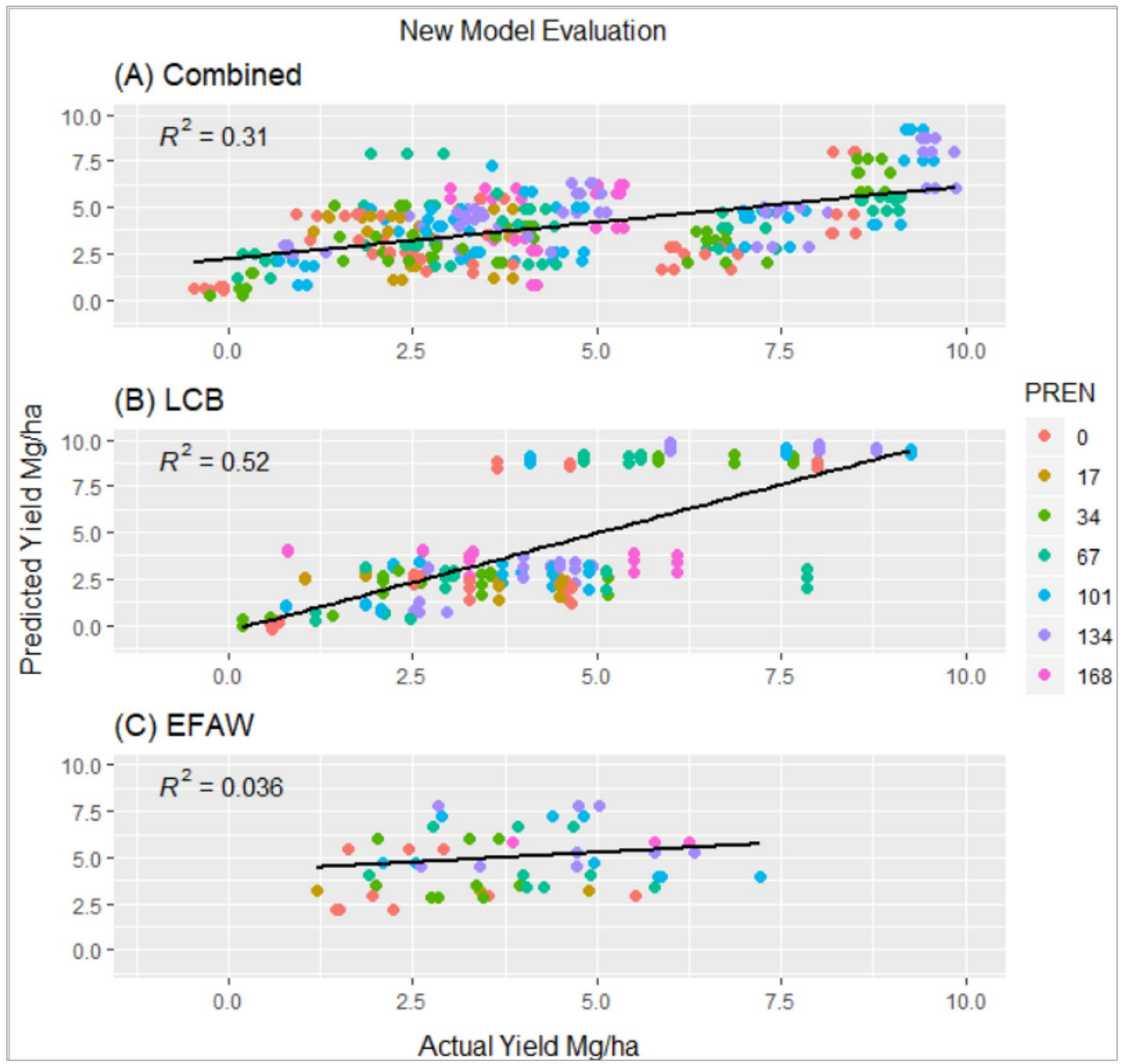

Figure 3. Validation of new models at different preplant $\mathrm{N}$ rates (PREN) on Optimum $\mathrm{N}$ rate trial, using combined data with the combined model (A), using LCB data with LCB model (B), using Efaw data with Efaw model (C).

average monthly soil temperature $100 \mathrm{~mm}$ under bare soil for August (BAVG-8). The last variable included was S25AVG-7.

New model validation. The combined model performed better than current algorithms when tested on all site years of optimum $\mathrm{N}$ rate. The coefficient of determination $\left(\mathrm{R}^{2}\right)$ between actual yield and model predicted yield was 0.31 (Fig. 3); a figure higher than that of any existing algorithms. The LCB model was best at predicting final grain yield with an $\mathrm{R}^{2}=0.52$. The Efaw model was unable to predict final grain yield and only explained $3.6 \%$ of the actual grain yield.

\section{Discussion}

The INSEY approach could result in overestimation of potential yield ${ }^{23,31}$. This happened while testing the current algorithm 1 and 2. The high PREN rates resulted in higher NDVI values. Incidentally, the projected biomass produced per day was large with relatively lower GDD. Extreme changes in growing condition from sensing to harvesting would lower the actual yield creating a vast difference in real and predicted yields ${ }^{31}$. This could be avoided by supplementing INSEY with more risk aversion prediction models ${ }^{31}$. Furthermore, locally developed algorithms do not perform outside the region for which they were designed ${ }^{32}$. All three current OSU algorithms were built on data before 2010, and any inconsistency in newer data (environment, genetics, soil types, etc.) would affect their efficiency. Moreover, temporal restriction needs to be considered, necessitating consistent upgrading of these algorithms.

In this study, we employed supervised learning category of ML involving 66 explanatory variables for yield prediction. After removing highly correlated variables, only 15 variables remained, and those were used to build new models. Puntel et al. ${ }^{28}$ developed new models using ML for the central-west region of Argentina. We 


\begin{tabular}{|l|l|}
\hline Location & Soil series \\
\hline Efaw & Ashport silty clay loam (fine-silty, mixed, superactive, thermic Fluventic Haplustolls) \\
\hline Lake Carl Blackwell & Port silt loam (fine-silty, mixed, thermic Cumulic Haplustolls) \\
\hline
\end{tabular}

Table 2. Description of soil series at Efaw and Lake Carl Blackwell, OK.

\begin{tabular}{|c|c|c|c|c|}
\hline \multirow[b]{2}{*}{ Trial (replication) } & \multirow[b]{2}{*}{ Location } & \multicolumn{2}{|l|}{$\mathbf{N}$} & \multirow[b]{2}{*}{ Plot size } \\
\hline & & Source & Preplant Rate $\left(\mathrm{kg} \mathrm{N} \mathrm{ha}^{-1}\right)$ & \\
\hline \multirow{2}{*}{ Corn regional (3) } & LCB & UAN $(28-0-0)$ & $0,45,90,134,179,224$ & $3.0 \mathrm{~m} \times 6.1 \mathrm{~m}$ \\
\hline & Efaw & UAN $(28-0-0)$ & $0,45,90,134,179,224$ & $3.0 \mathrm{~m} \times 6.1 \mathrm{~m}$ \\
\hline \multirow{2}{*}{ Optimum N trial (3) } & LCB & UAN $(28-0-0)$ & $0,17,34,67,101,134,168$ & $3.0 \mathrm{~m} \times 6.1 \mathrm{~m}$ \\
\hline & Efaw & UAN $(28-0-0)$ & $0,17,34,67,101,134,168$ & $3.0 \mathrm{~m} \times 6.1 \mathrm{~m}$ \\
\hline
\end{tabular}

Table 3. Nitrogen fertilizer application rate used for model testing and training of this study.

developed predictive models for yield potential by combining optical sensors and climatological data. In agreement with Puntel et al. ${ }^{28}$, our models use fewer inputs than a simulation models.

Furthermore, our models are significant in comparison to the other current methodologies and account for spatial and temporal variability, appropriate for application in precision agriculture. In-season $\mathrm{N}$ assessment using optical sensor is a promising approach over other traditional methods ${ }^{13,14,23,33,34}$. However, their precision depends on the accuracy of algorithms that convert crop reflectance to yield prediction and $\mathrm{N}$ recommendation ${ }^{13}$. Analogous to this, we tried to develop regional algorithms to closely mimic factors such as current crop variety, rainfall, soils, timing, form, and placement of $\mathrm{N}$, and interactions of these factors to determine potential yield and recommend $\mathrm{N}$ rates regionally as highlighted by ${ }^{13}$.

Bushong et al. ${ }^{8}$ stressed proper validation of developed prediction models, to determine the accuracy of models to predict grain yield on an independent data set. They further highlighted the scarcity of work that validates yield prediction models. Numerous models explain the goodness of fit of the data used to develop the model without validation with an independent data set ${ }^{15,17,21,23-25,31,35}$. Our new models were independently validated, and where two out of three models performed well with a prediction accuracy of $31 \%$ and $52 \%$.

\section{Conclusion}

In this work, an attempt to derive data-driven recommendations using NDVI and weather information currently collected by Mesonet weather stations was made. These regional models have the efficiency to explain final grain yield with $67 \%, 83 \%$, and $85 \%$ accuracy, which is a crucial step for making $\mathrm{N}$ recommendations. When tested on an independent data set these models accurately predicted $31 \%$ and $52 \%$ final grain yield. However, in the future, it is essential to keep these models apprised with newer data.

\section{Methods}

Site description. The corn regional experiment (Regional) was set up in a randomized complete block design with 12 treatments replicated three times. This trial was initiated to update the algorithms used for yield prediction and subsequent $\mathrm{N}$ rate recommendation. A total of 7 site-years of data were included in this study. Data from Lake Carl Blackwell (LCB) from 2015 to 2018 were used. Three-years of data from 2016 to 2018 from Efaw Agronomy Research Station (Efaw) were also included. This experiment was further used to train/build three new models for yield prediction.

Similarly, a randomized complete block experimental design with three replications at all sites with fourteen treatments was used for the Optimum $\mathrm{N}$ rate experiment (Optimum N). This study was initiated to predict the optimum preplant $\mathrm{N}$ rates for the region. Similar to the Regional trial, a total of 7 site-years of data were included in this study. Data from four years at LCB and three at Efaw were analyzed. Both experiments were fertilized to a $100 \%$ level based on $\mathrm{P}$ and $\mathrm{K}$ test following regional fertilizer recommendations ${ }^{36}$, to ensure $\mathrm{N}$ was the only limiting nutrient. This trial was further used to validate/test new models built using regional corn data. Soil descriptions for each site are reported in Table 2.

For all sites, only treatments with no $\mathrm{N}$ fertilizer or preplant $\mathrm{N}$ (PREN) fertilizer applications were included in this study. Treatments with mid-season $\mathrm{N}$ application were excluded. A total of six treatments from Regional, and seven treatments from Optimum $\mathrm{N}$ trial were included. The treatments and $\mathrm{N}$ rates included for each trial location are listed in Table 3.

Field data collection. Throughout the growing season, NDVI data were collected using a hand-held Greenseeker sensor from V4 to V8 growth stages. The GreenSeeker sensor measured NDVI by utilizing the Eq. (1):

$$
\mathrm{NDVI}=\frac{\rho N I R-\rho R E D}{\rho N I R+\rho R E D}
$$




\begin{tabular}{|l|l|l|}
\hline Acronym & Explanation & Unit \\
\hline MarR, AprR, MayR, JunR, JulR, AugR, SepR & Average monthly rainfall from March to September & mm \\
\hline TAVG-3,TAVG-4,TAVG-5,TAVG-6,TAVG-7,TAVG-8,TAVG-9 & Average monthly air temperature from March to September & Degrees celsius (C) \\
\hline SAVG-3,SAVG-4,SAVG-5,SAVG-6,SAVG-7,SAVG-8,SAVG-9 & $\begin{array}{l}\text { Average monthly soil temperature } 100 \mathrm{~mm} \text { under sod from March to Septem- } \\
\text { ber }\end{array}$ & C \\
\hline BAVG-3,BAVG-4,BAVG-5,BAVG-6,BAVG-7,BAVG-8,BAVG-9 & $\begin{array}{l}\text { Average monthly soil temperature } 100 \mathrm{~mm} \text { under bare soil from March to } \\
\text { September }\end{array}$ & C \\
\hline S5AVG-3,S5AVG-4,S5AVG-5,S5AVG-6,S5AVG-7,S5AVG-8,S5AVG-9 & $\begin{array}{l}\text { Average monthly soil temperature } 50 \text { mm under sod from March to Septem- } \\
\text { ber }\end{array}$ & C \\
\hline S25AVG-3,S25AVG-4,S25AVG-5,S25AVG-6,S25AVG-7,S25AVG-8,S25AVG-9 & $\begin{array}{l}\text { Average monthly soil temperature } 250 \mathrm{~mm} \text { under sod from March to Septem- } \\
\text { ber }\end{array}$ & C \\
\hline S60AV-3,S60AV-4,S60AV-5,S60AV-6,S60AV-7,S60AV-8,S60AV-9 & $\begin{array}{l}\text { Average monthly soil temperature } 600 \text { mm under sod from March to Septem- } \\
\text { ber }\end{array}$ & C \\
\hline FWI05-3,FWI05-4,FWI05-5,FWI05-6,FWI05-7,FWI05-8,FWI05-9 & $\begin{array}{l}\text { Monthly Fractional water index at 50 mm for each month from March to } \\
\text { September }\end{array}$ & Unitless \\
\hline FWI25-3,FWI25-4,FWI25-5,FWI25-6,FWI25-7,FWI25-8,FWI25-9 & Fractional water index at 250 mm for each month from March to September & Unitless \\
\hline
\end{tabular}

Table 4. Description of all the explanatory variables used in this study.

where near-infrared (NIR) was measured at $780 \mathrm{~nm}$ and red at $650 \mathrm{~nm}^{37}$. A self-propelled Massey Ferguson $8 X P$ Combine (AGCO Corp., Duluth, GA, USA) equipped with harvest master (Juniper Systems Inc., Logan, UT, USA) automated weighing systems were used for harvesting the center two of four-row plots. The final yield was adjusted to $15.5 \%$ moisture content.

The weather data was taken from the Oklahoma Mesonet climate monitoring station ${ }^{38}$. Sensor data was normalized to calculate a fractional water index (FWI), which is a unitless value ranging from 0.00 for dry soils to 1.00 for the wet/saturated soils ${ }^{39}$. The list of all the other explanatory variables included in this study is listed in Table 4.

Data analysis. Evaluation of a current model for yield prediction. Three algorithms from (https://www.nue. okstate.edu/Yield_Potential.htm) were evaluated to predict yield potential. All these algorithms were made using the methodology described by Raun et al. ${ }^{23}$. A linear regression analysis among predicted and actual yield was conducted to check the efficiency of these algorithms. This was done on both regional and optimum $\mathrm{N}$ rate data with the combined data and then for each location separately.

The following algorithms were used:

1. $\mathrm{YP0}=2,592 \times(\mathrm{EXP}(\mathrm{NDVI} / \mathrm{Sum}$ of GDD $\times 1775.6) ; \mathrm{RI}$ Harvest $=1.64(\mathrm{RI}-\mathrm{NDVI})-0.5287$

2. $\mathrm{YP} 0=1,287 \times(\mathrm{EXP}(\mathrm{NDVI} / \mathrm{Sum}$ of GDD $\times 2,655)$; RI Harvest $=1.64(\mathrm{RI}$ NDVI $)-0.5287$

3. $\mathrm{YP} 0=($ CoefA $\times \mathrm{EXP}(\mathrm{CoefB} \times \mathrm{NDVI}))$; RI Harvest $=1.64(\mathrm{RI}-\mathrm{NDVI})-0.5287$

CoefA $=641.4158203057011+4207.148880805758 /(1.0+\operatorname{EXP}(-(x-897.0822110817790) /$ $(-32.78891349907328)))$

$\mathrm{CoefB}=1.46923333343772+1.8752166665474 /(1+\operatorname{EXP}(-(\mathrm{x}-912.164821648278) / 2.66689327528455$ )

$(\mathrm{x}=$ cumulative GDD)

Training new models for yield prediction. New models for yield prediction were trained using data from the regional trial and climatological data obtained from the Oklahoma Mesonet climate monitoring station. A total of 66 explanatory variables were included for a multiple linear regression model comprised of preplant $\mathrm{N}$ rate, NDVI, Growing degree day heat units (GDD) along with weather variables listed in Table 4. The NDVI data were used for the growth stages from V4 to V8, and due to inconsistency in data collection, the new models were not separated for each growth stage. The climatological variables included encompassed the months of March to September.

Following steps were taken to generate the new models:

1. A Pearson correlation test was conducted for all the explanatory variables to remove highly correlated variables. The R statistical package "Hmisc" was used to calculate correlation coefficients and p-values. For plotting correlograms R package, "corrplot" was used.

2. Highly correlated variables were excluded from subsequent regression analysis; a reduced number of variables were used in the next step.

3. Best subset selection was used to identify a subset of variables. This reduced set was then fitted using least squares to predict yield. The single best model was then selected using cross-validation prediction error (Cp), Akaike information criterion (AIC), Bayesian information BIC, and adjusted $\mathrm{R}^{2}$. All these approaches estimate test error by adjusting the training error to account for overfitting due to the bias ${ }^{40}$. The branch and bound algorithm within "leaps" package of R statistical software ${ }^{41}$ were used for best sub selection.

4. Three different linear regression models were developed. The first one using all of the data from regional termed as the combined model and the other two for each location, LCB, and Efaw, respectively. 
Testing new model for yield prediction. The new models were tested on Optimum $\mathrm{N}$ trials. The three new models were tested by conducting a correlation between model predicted yields and actual yields. The combined model was tested on all of the data from Optimum N experiment. Only LCB data from Optimum N trial was used to validate the LCB model, and similarly, Efaw Optimum $\mathrm{N}$ data was used to check the Efaw model.

Received: 24 January 2020; Accepted: 24 June 2020

Published online: 10 July 2020

\section{References}

1. Lu, C. C. \& Tian, H. Global nitrogen and phosphorus fertilizer use for agriculture production in the past half-century: shifted hot spots and nutrient imbalance. Earth Syst. Sci. Data 9, 181 (2017).

2. Dhillon, J., Torres, G., Driver, E., Figueiredo, B. \& Raun, W. R. World phosphorus use efficiency in cereal crops. Agron. J. 109, 1670-1677 (2017).

3. Dhillon, J. S., Eickhoff, E. M., Mullen, R. W. \& Raun, W. R. World potassium use efficiency in cereal crops. Agron. J. 111, 889-896 (2019).

4. Raun, W. R. \& Johnson, G. V. Improving nitrogen use efficiency for cereal production. Agron. J. 91, 357-363 (1999).

5. Lassaletta, L., Billen, G., Grizzetti, B., Anglade, J. \& Garnier, J. 50-year trends in nitrogen use efficiency of world cropping systems: the relationship between yield and nitrogen input to cropland. Environ. Res. 9, 105011 (2014).

6. Omara, P., Aula, L., Oyebiyi, F. \& Raun, W. R. World cereal nitrogen use efficiency trends: review and current knowledge. Agron. Geosci. Environ. 2, 180045. https://doi.org/10.2134/age2018.10.0045 (2019).

7. Raun, W. R. et al. In-season prediction of potential grain yield in winter wheat using canopy reflectance. Agron. J. 93, 131-138 (2001).

8. Bushong, J. T. et al. Development of an in-season estimate of yield potential utilizing optical crop sensors and soil moisture data for winter wheat. Prec. Agric. 17, 451-469 (2016).

9. Raun, W. et al. Can yield goals be predicted?. Agron. J. 109, 2389-2395 (2017).

10. Rodriguez, D. G. P., Bullock, D. S. \& Boerngen, M. A. The origins, implications, and consequences of yield-based nitrogen fertilizer management. Agron. J. 111, 723-735 (2019).

11. Bushong, J. T., Mullock, J. L., Arnall, D. B. \& Raun, W. R. Effect of nitrogen fertilizer source on corn (Zea mays L.) optical sensor response index values in a rain-fed environment. J. Plant Nutr. 41, 1172-1183 (2018).

12. Lukina, E. V. et al. Nitrogen fertilization optimization algorithm based on in-season estimates of yield and plant nitrogen uptake. J. Plant Nutr. 24, 885-898 (2001).

13. Morris, T. F. et al. Strengths and limitations of nitrogen rate recommendations for corn and opportunities for improvement. Agron. J110, 1-37 (2018).

14. Raun, W. R. et al. Improving nitrogen use efficiency in cereal grain production with optical sensing and variable rate application. Agron. J. 94, 815-820 (2002).

15. Sharma, L. K., Bali, S. K., Zaeen, A. A., Baldwin, P. \& Franzen, D. W. Use of rainfall data to improve ground-based active optical sensors yield estimates. Agron. J. 110, 1561-1571 (2018).

16. Stone, M. L. et al. Use of spectral radiance for correcting in-season fertilizer nitrogen deficiencies in winter wheat. Trans. ASABE 39, 1623-1631 (1996).

17. Tagarakis, A. C. \& Ketterings, Q. M. In-season estimation of corn yield potential using proximal sensing. Agron. J. 109, 1323-1330 (2017).

18. Franzen, D., Kitchen, N., Holland, K., Schepers, J. \& Raun, W. Algorithms for in-season nutrient management in cereals. Agron. J. 108, 1775-1781 (2016)

19. Moges, S. M. et al. In-season estimation of grain sorghum yield potential using a hand-held optical sensor. Arch. Agron. Soil Sci. 53, 617-628 (2007).

20. Hatfield, J. L., Gitelson, A. A., Schepers, J. S. \& Walthall, C. L. Application of spectral remote sensing for agronomic decisions. Agron. J. 100(Supplement_3), S117 (2008).

21. Sharma, L. K. \& Franzen, D. W. Use of corn height to improve the relationship between active optical sensor readings and yield estimates. Prec. Agric. 15, 331-345 (2014).

22. Solie, J. B., Raun, W. R., Whitney, R. W., Stone, M. L. \& Ringer, J. D. Optical sensor based field element size and sensing strategy for nitrogen application. Trans. ASABE 39, 1983-1992 (1996).

23. Raun, W. R. et al. Optical sensor-based algorithm for crop nitrogen fertilization. Commun. Soil Sci. Plan. 36, 2759-2781 (2005).

24. Girma, K. et al. Midseason prediction of wheat-grain yield potential using plant, soil, and sensor measurements. J. Plant Nutr. 29, 873-897 (2006).

25. Walsh, O. S., Klatt, A. R., Solie, J. B., Godsey, C. B. \& Raun, W. R. Use of soil moisture data for refined Greenseeker sensor-based nitrogen recommendations in winter wheat (Triticum aestivum L.). Prec. Agric. 14, 343-356 (2013).

26. Martin, K., Raun, W. \& Solie, J. By-plant prediction of corn grain yield using optical sensor readings and measured plant height. J. Plant Nutr. 35, 1429-1439 (2012).

27. Qin, Z. et al. Application of machine learning methodologies for predicting corn economic optimal nitrogen rate. Agron. J. https:// doi.org/10.2134/agronj2018.03.0222 (2018).

28. Puntel, L. A., Pagani, A. \& Archontoulis, S. V. Development of a nitrogen recommendation tool for corn considering static and dynamic variables. Eur. J. Agron. 105, 189-199 (2019).

29. Raun, W. et al. Unpredictable nature of environment on nitrogen supply and demand. Agron. J. https://doi.org/10.2134/agronj2019. 04.0291 (2019).

30. Baath, G. S., Northup, B. K., Rocateli, A. C., Gowda, P. H. \& Neel, J. P. Forage potential of summer annual grain legumes in the southern great plains. Agron. J. 111, 2198-2210 (2018).

31. Tubaña, B. S. et al. Adjusting midseason nitrogen rate using a sensor-based optimization algorithm to increase use efficiency in corn. J. Plant Nutr. 31, 1393-1419 (2008).

32. Bean, G. M. et al. Active-optical reflectance sensing corn algorithms evaluated over the United States Midwest Corn Belt. Agron. J. https://doi.org/10.2134/agronj2018.03.0217 (2018).

33. Kitchen, N. R. et al. Ground-based canopy reflectance sensing for variable-rate nitrogen corn fertilization. Agron. J. 102, 71-84 (2010).

34. Scharf, P. C. et al. Sensor-based nitrogen applications out-performed producer-chosen rates for corn in on-farm demonstrations. Agron. J. 103, 1683-1691 (2011).

35. Bean, G. M. et al. Improving an active-optical reflectance sensor algorithm using soil and weather information. Agron. J. https:// doi.org/10.2134/agronj2017.12.0733 (2018).

36. Zhang, H. \& Raun, W. R. Oklahoma Soil Fertility Handbook 6th edn. (Oklahoma State University Press, Stillwater, 2006).

37. Dhillon, J. S. et al. Evaluation of drum cavity size and planter tip on singulation and plant emergence in maize (Zea mays L.). J. Plant Nutr. 40, 2829-2840 (2017). 
38. Oklahoma Mesonet. Daily data retrieval. University of Oklahoma. https://www.mesonet.org/index.php/weather/category/past_ data_files. Accessed $1 \mathrm{Feb} 2019$ (2019).

39. Illston, B. G. et al. Mesoscale monitoring of soil moisture across a statewide network. J. Atmos. Ocean. Technol. 25, 67-182 (2008).

40. James, G., Witten, D., Hastie, T. \& Tibshirani, R. An Introduction to Statistical Learning 18 (Springer, New York, 2013).

41. R Core Team. R: A Language and Environment for Statistical Computing. Retrieved (https://www.r-project.org/) (2019).

\section{Acknowledgements}

The authors would like to thank the Oklahoma Soil Fertility Research and Education Advisory Board for their funding of this research project and their continued financial support of soil fertility research at Oklahoma State University. The authors would also like to express their sincere gratitude to all the current and former soil fertility graduate students who aided in the data collection and maintenance of trials.

\section{Author contributions}

J.D. and W.R. conceived the experiment, J.D., A.L. and E.E. collected the field data, J.D. and W.R. wrote the main manuscript. All the authors reviewed the manuscript.

\section{Competing interests}

The authors declare no competing interests.

\section{Additional information}

Correspondence and requests for materials should be addressed to J.D.

Reprints and permissions information is available at www.nature.com/reprints.

Publisher's note Springer Nature remains neutral with regard to jurisdictional claims in published maps and institutional affiliations.

(c) Open Access This article is licensed under a Creative Commons Attribution 4.0 International License, which permits use, sharing, adaptation, distribution and reproduction in any medium or format, as long as you give appropriate credit to the original author(s) and the source, provide a link to the Creative Commons license, and indicate if changes were made. The images or other third party material in this article are included in the article's Creative Commons license, unless indicated otherwise in a credit line to the material. If material is not included in the article's Creative Commons license and your intended use is not permitted by statutory regulation or exceeds the permitted use, you will need to obtain permission directly from the copyright holder. To view a copy of this license, visit http://creativecommons.org/licenses/by/4.0/.

This is a U.S. Government work and not under copyright protection in the US; foreign copyright protection may apply 2020 